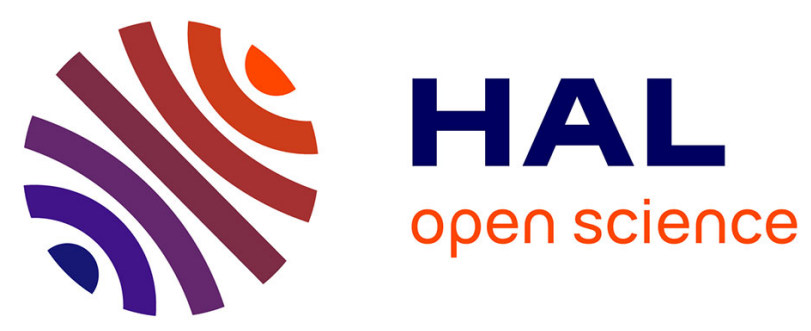

\title{
Reappraisal of archaeal C20-C25 diether lipid (extended archaeol) origin and use as a biomarker of hypersalinity
}

Flore Vandier, Maxime Tourte, Cara Doumbe-Kingue, Julien Plancq, Philippe Schaeffer, Phil Oger, Vincent Grossi

\section{- To cite this version:}

Flore Vandier, Maxime Tourte, Cara Doumbe-Kingue, Julien Plancq, Philippe Schaeffer, et al.. Reappraisal of archaeal C20-C25 diether lipid (extended archaeol) origin and use as a biomarker of hypersalinity. Organic Geochemistry, In press, 10.1016/j.orggeochem.2021.104276 . hal-03289860

\section{HAL Id: hal-03289860 https://hal.science/hal-03289860}

Submitted on 19 Jul 2021

HAL is a multi-disciplinary open access archive for the deposit and dissemination of scientific research documents, whether they are published or not. The documents may come from teaching and research institutions in France or abroad, or from public or private research centers.
L'archive ouverte pluridisciplinaire HAL, est destinée au dépôt et à la diffusion de documents scientifiques de niveau recherche, publiés ou non, émanant des établissements d'enseignement et de recherche français ou étrangers, des laboratoires publics ou privés. 
archives-ouvertes

\section{Reappraisal of archaeal C20-C25 diether lipid (extended archaeol) origin and use as a biomarker of hypersalinity}

Flore Vandier, Maxime Tourte, Cara Doumbe-Kingue, Julien Plancq, Philippe Schaeffer, Phil Oger, Vincent Grossi

\section{- To cite this version:}

Flore Vandier, Maxime Tourte, Cara Doumbe-Kingue, Julien Plancq, Philippe Schaeffer, et al.. Reappraisal of archaeal C20-C25 diether lipid (extended archaeol) origin and use as a biomarker of hypersalinity. Organic Geochemistry, Elsevier, 2021, 10.1016/j.orggeochem.2021.104276 hal-03289860

\section{HAL Id: hal-03289860 \\ https://hal.archives-ouvertes.fr/hal-03289860}

Submitted on 19 Jul 2021

HAL is a multi-disciplinary open access archive for the deposit and dissemination of scientific research documents, whether they are published or not. The documents may come from teaching and research institutions in France or abroad, or from public or private research centers.
L'archive ouverte pluridisciplinaire HAL, est destinée au dépôt et à la diffusion de documents scientifiques de niveau recherche, publiés ou non, émanant des établissements d'enseignement et de recherche français ou étrangers, des laboratoires publics ou privés. 
Note

\title{
Reappraisal of archaeal $\mathrm{C}_{20}-\mathrm{C}_{25}$ diether lipid (extended archaeol) origin and use as a biomarker of hypersalinity
}

\author{
Flore Vandier ${ }^{\mathrm{a}}$, Maxime Tourte ${ }^{\mathrm{b}}$, Cara Doumbe-Kingue ${ }^{\mathrm{b}}$, Julien Plancq ${ }^{\mathrm{c}}$, Philippe Schaeffer ${ }^{\mathrm{d}}$, \\ Phil Oger ${ }^{\mathrm{b}}$, Vincent Grossi ${ }^{\mathrm{a}}$ * \\ a Univ. Lyon, UCBL, ENSL, UJM, CNRS, LGL-TPE, F-69622 Villeurbanne, France \\ ${ }^{\mathrm{b}}$ Univ. Lyon, INSA Lyon, CNRS, UMR 5240, F-69621 Villeurbanne, France \\ ${ }^{\mathrm{c}}$ School of Geographical and Earth Sciences, University of Glasgow, Scotland, UK \\ ${ }^{\mathrm{d}}$ Univ. Strasbourg, CNRS, UMR 7177, F-67000 Strasbourg, France
}

\section{A R T I C L E I N F O}

\section{Article history:}

Received 1 April 2021

Received in revised form 8 July 2021

Accepted 9 July 2021

\section{Keywords:}

Halophilic archaea

Extended archaeol

Adaptation to $\mathrm{pH}$ and salinity

Natrialbales

\begin{abstract}
A B S T R A C T
The diether core membrane lipid sesterterpanyl-phytanyl-glycerol (so-called extended archaeol and often abbreviated $\mathrm{C}_{20}-\mathrm{C}_{25}$ ) is considered as a hallmark of Haloarchaea, a clade of archaea thriving under extreme high salinities. We here report about extended archaeol occurrence in different saline aquatic settings with salinity ranging from ca. $50 \mathrm{psu}(5 \% \mathrm{NaCl}$ w/v) to saturation (ca. $350 \mathrm{psu}$ ). This demonstrates that this lipid is not restricted to extreme saline environments but suggests a minimum salinity threshold of ca. 50 psu above which $\mathrm{C}_{20}-\mathrm{C}_{25}$ is most commonly produced. The proportion of $\mathrm{C}_{20}-\mathrm{C}_{25}$ relative to that of archaeol $\left(\mathrm{C}_{20}-\mathrm{C}_{20}\right)$ did not appear linearly dependent on the salinity of the site and was potentially also influenced by $\mathrm{pH}$ and temperature, preventing its direct use as a quantitative salinity proxy based on the present data set. An extensive literature review of archaeal membrane lipid compositions further highlighted that taxonomy also contributes to the distribution of this lipid in the environment and identifies Natrialbales (one of the three orders of Haloarchaea) as the main source. Statistical analysis showed that, among Haloarchaea, $\mathrm{C}_{20}-\mathrm{C}_{25}$ producers display $\mathrm{pH}$ and salinity growth optima slightly higher than non-producers and are distributed within two distinct groups, one composed mostly of neutrophiles and one of alkaliphiles. In contrast, the presence of $C_{20}-C_{25}$ was not correlated to the optimal growth temperature of the strains. This suggests that two confounding parameters, i.e., taxonomy and adaptation to changes in salinity and/or $\mathrm{pH}$, contribute to the distribution of $\mathrm{C}_{20}-\mathrm{C}_{25}$ within Haloarchaea.
\end{abstract}

\section{Introduction}

Isoprenoid dialkyl glycerol diether lipids are membrane lipids unique to the Archaea. Archaeol 1 (2,3-di-O-phytanyl-sn-glycerol; Fig. $1 \mathrm{~A})$ and its elongated homologue called extended archaeol 2 (2-Osesterterpanyl-3-O-phytanyl-sn-glycerol 2a and its regiosiomer 2-Ophytanyl-3-O-sesterterpanyl-sn-glycerol 2b; Fig. 1A) are the two main types of archaeal diether lipids encountered. While $\mathbf{1}$ is globally distributed among Archaea (e.g., Tourte et al., 2020), 2 was initially described only in haloalkaliphilic archaea (De Rosa et al., 1982) before being detected in non-alkaline hypersaline environments (Teixidor et al., 1993) and later on considered as a hallmark of halophilic Euryarchaeota from the clade Haloarchaea (Dawson et al., 2012 and references therein). However, few exceptions exist outside this clade (e.g., Becker et al., 2016). The extra isoprenoid unit on either one of the alkyl chains in 2

\footnotetext{
* Corresponding author.

E-mail address: Vincent.grossi@univ-lyon1.fr (V. Grossi).
}

compared to 1 results in an asymmetric lipid that was hypothesized to induce "zip-like" archaeal membranes specifically adapted to high alkalinity and strong osmotic stress (De Rosa et al., 1982). The detection of 2 in sedimentary archives has been consequently associated with the presence of Haloarchaea and used as a marker of hypersaline/evaporitic environments (Birgel et al., 2014). Although relevant to some extent, the distribution of $\mathbf{2}$ in both Archaea and environmental samples as well as its physiological and adaptive functions still remain incompletely understood. For instance, this compound has been reported in ancient marine sequences showing no lithological evidence of high salinities (Natalicchio et al., 2017). On the other hand, preliminary results based on laboratory cultures of a single Haloarchaea species (from the order Halobacteriales) have shown that the relative proportion of 2 increases with increasing temperature and salinity (Yamauchi, 2008), while its occurrence within a few Haloarchaea species appeared related to taxonomy and optimal $\mathrm{NaCl}$ concentration (Dawson et al., 2012). Here, we report the presence of $\mathbf{2}$ in surface sediments from aquatic environments with diverse salinities, and reinvestigate its occurrence in 
A)

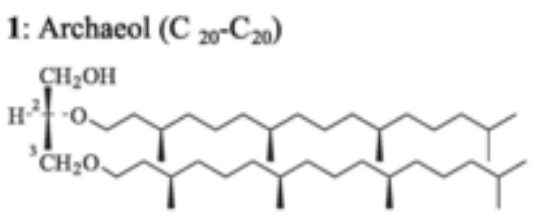

2: Extended archaeol

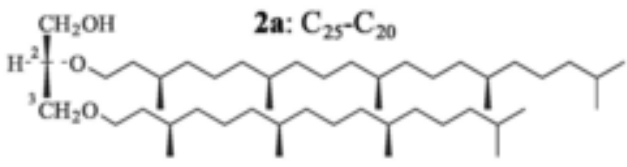

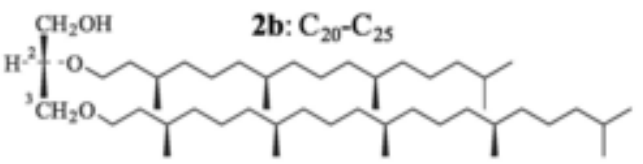

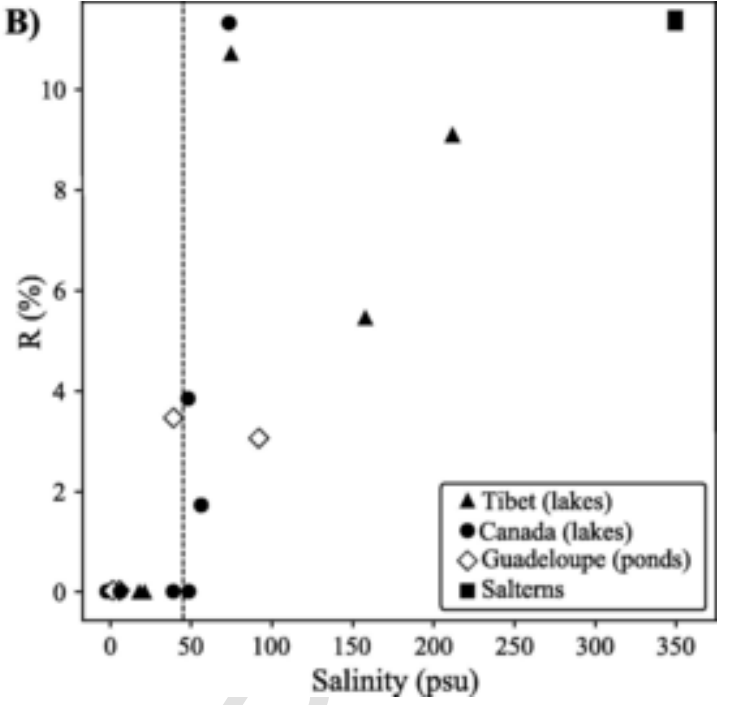

Fig. 1. A) Structures of archaeol 1 and the two possible regioisomers of extended archaeol 2; B) Proportion of 2 relative to 1 in superficial sediments of lakes and ponds with different salinities. The dashed line indicates a possible threshold for the presence of 2 around $40-50 \mathrm{psu}$. $\mathrm{R}=\mathbf{2} /(\mathbf{1}+\mathbf{2}) \times 100$.

(halo)archaea based on an extensive literature survey to better constrain its biological origin and potential use as a (paleo)environmental indicator.

\section{Material and methods}

\subsection{Sediment samples and lipid analysis}

Surface sediments coming from 31 sites with a salinity ranging from 0 practical salinity unit (psu) to saturation (ca. $350 \mathrm{psu}$ ) were investigated for the presence of $\mathbf{1}$ and $\mathbf{2}$ (Table S1). The different sites include lakes from the Canadian Prairies (Plancq et al., 2018) and the Tibetan Plateau (Wang et al., 2020), salterns from France (Camargue) and Argentina (Valdes Peninsula) and saline ponds from Guadeloupe (Huguet et al., 2015). Some sediments have been analyzed in previous studies while other were specifically considered for the present work (Table S1). Sediment samples were freeze-dried and extracted ultrasonically [methanol $(\mathrm{MeOH}) \mathrm{x} 2$, dichloromethane $(\mathrm{DCM}) / \mathrm{MeOH}(1: 1, \mathrm{v} / \mathrm{v}) \times 2$, $\mathrm{DCM} \times 2$ ] or using an automated solvent extractor (Huguet et al., 2015; Plancq et al., 2018). The total lipid extracts were chromatographed over a silica gel column with hexane (Hex), Hex/DCM $(1: 1, \mathrm{v} / \mathrm{v}), \mathrm{Hex} / \mathrm{ethyl}$ acetate $(3: 1, \mathrm{v} / \mathrm{v})$, and DCM/MeOH $(1: 1, \mathrm{v} / \mathrm{v})$ as eluents. The third fraction, which contained free alcohols, was silylated with pyridine/N,O-bis(trimethylsilyl)trifluoroacetamide $(1: 1, \mathrm{v} / \mathrm{v})$ and analyzed by gas-chromatography - mass spectrometry (GC-MS) using an Agilent 6890 gas chromatograph coupled to an Agilent 5975C mass spectrometer. Compounds were injected on column and separated on a HP5-MS capillary column $(30 \mathrm{~m} \times 0.25 \mathrm{~mm} \times 0.25 \mu \mathrm{m})$ using the following GC oven temperature program: $60{ }^{\circ} \mathrm{C}$ held for $0.5 \mathrm{~min}$, $20{ }^{\circ} \mathrm{C} \mathrm{min}-1$ to $130{ }^{\circ} \mathrm{C}$ then $4{ }^{\circ} \mathrm{C} \mathrm{min}-1$ to $300{ }^{\circ} \mathrm{C}$ held for $45 \mathrm{~min}$. The temperature of the on-column injector was programmed as followed: $60{ }^{\circ} \mathrm{C}$ held for $0.5 \mathrm{~min}, 200{ }^{\circ} \mathrm{C} \mathrm{min}-1$ to $300{ }^{\circ} \mathrm{C}$ held for $1 \mathrm{~min}$. Total Ion Current (TIC) and Selected Ion Monitoring (SIM) of the ions $m / z 130$, 131, 426 and 496 (specific of silylated derivatives of 1 and 2; Teixidor et al., 1993) were recorded. Due to the low amount of 2 and/or compounds coeluting with 1 in some samples, the abundance of 2 relative to $1+\mathbf{2}(\mathrm{R})$ was determined from the peak area measured on the SIM chromatograms, with $\mathrm{R}=2 /(1+2) \times 100$. It should be noted, however, that when both measurements were possible, SIM and TIC signals yielded comparable $\mathrm{R}$ values (Table $\mathrm{S} 1$ ).

\subsection{Literature survey and statistical analyses}

Information on the membrane lipid compositions of all Archaea species reported in the literature was collected $(\mathrm{N}=450)$. To estimate the influence of growth parameters on the production of 2, Haloarchaea $(\mathrm{N}=277)$ were sorted between 2-positive and 2-negative species and their optimal growth conditions (salinity, $\mathrm{pH}$ and temperature) were compared using a non-parametric test on medians performed with the Python statistical package, as data were not normally distributed. Medians were considered significantly different when $P$-values were below 0.05 .

\section{Results and discussion}

Compounds 1 and 2 were detected in 19 and 10 out of the 31 samples analyzed, respectively. Other isoprenoid diether lipids [e.g., (macro)cyclic or hydroxylated1] were not detected besides $\mathbf{1}$ and $\mathbf{2}$. Among the 19 lakes where $\mathbf{1}$ was observed, $\mathbf{2}$ was detected in all sites with a salinity around or above 50 psu, yielding $R$ values between 1.7 and $11.3 \%$, and was not detected in lakes with a salinity lower than 50 psu except in one saline pond from Guadeloupe with a salinity of ca. 41 psu (Fig. 1B; Table S1). Although sediments from hypersaline ponds with the highest salinity (ca. $350 \mathrm{psu}$, close to saturation level) displayed the highest proportions of 2 ( $\mathrm{R}$ values of ca. $11 \%$ ), similar proportions of $\mathbf{2}$ were also observed in sites with a salinity between 70 and 210 psu (Fig. 1B). These results support 2 as a biomarker of hypersaline environments as previously suggested (Teixidor et al., 1993; Birgel et al., 2014), but further show that this biomarker is not restricted to extreme saline environments, extending its use to settings with a salinity down to ca. $40-50$ psu. This is in line with the occurrence of 2 in Miocene shales, marls and carbonates which are supposed to have formed under non-extreme conditions of salinity (Natalicchio et al., 2017). The proportion of $\mathbf{2}$ did not appear linearly dependent on salinity (Fig. 1B), preventing the definition of a quantitative salinity proxy given the present data set. It is possible, however, that some uncertainties linked to the ways salinity was measured for the different sites (Table S1) may have obscured such a potential linear relationship between the relative proportion of $\mathbf{2}$ and salinity. On the other hand, the possibility that a sediment sample reflects different salinity conditions than those at the time of sampling is not likely since only the surficial sediments were analyzed and none of the 'low-salt' sediments in which 2 was detected enclosed evaporites which could have attested from past hypersaline conditions. It may also be envisaged that the occurrence of 
2 further depends on other environmental parameters such as $\mathrm{pH}$ or temperature. Because these limnological parameters were not available for all the studied sites (Table S1), their potential influence on the occurrence of $\mathbf{2}$ could only be partially investigated (Fig. S1). Still, for the limited set of data available, a potential influence of both variables on the proportion of 2 was noticed. $\mathrm{R}$ seemed to decrease with increasing in-situ temperature (in the range $15-30{ }^{\circ} \mathrm{C}$; Fig. S1A and Table S1) which contrasts with previous observations made using laboratory cultures of a single Haloarchaea species (Yamauchi, 2008). On the other hand, 2 was detected in sediments with $\mathrm{pH}$ values ranging from 7.5 to 9.4 (Fig. S1B and Table S1), pointing towards different $\mathrm{pH}$ conditions of production. Lastly, our analyses only considered the occurrence of $\mathbf{1}$ and 2 under their free forms [i.e., as core lipids (CL) without polar heads] and did not take into account the potential co-occurrence of these diethers as intact polar lipids (IPL), as found in living biomass. However, considering that $\mathbf{1}$ and $\mathbf{2}$ IPL are likely to exhibit similar polar heads, their hydrolysis rates during diagenesis are expected to be close to each other, thus limiting potential biases reflected in the $\mathrm{R}$ ratio based on CL analysis. Whether or not this ratio can become a quantitative environmental proxy remains to be further investigated. It would be of particular interest to determine if the biosynthesis of $\mathbf{2}$ scales with salinity (or other environmental parameters) within individual producers, and/or if the relative abundance of archaeal species producing this compound scales with salinity (or other variables).

To further explore potential adaptive functions of $\mathbf{2}$ towards salinity and other growth parameters, we looked for its occurrence among all the archaeal membrane lipid compositions available in the literature $(\mathrm{N}=450)$. It should be emphasized that all literature data was not homogeneous in the sense that some studies focused on IPL, whereas other studies reported CL compositions obtained after hydrolysis of total lipid extracts. Since our survey considered both IPL and CL, it should not be biased by the heterogeneity of the literature data. Compound 2 was reported in only 91 out of 450 species, with 87 species belonging to the three orders of Haloarchaea, i.e., the Halobacteriales, Haloferacales and Natrialbales. The 4 additional species producing 2, namely, Methanomassilicoccales luminyensis, Methanolobus tindarius, Methanosarcina barkeri and Methanosarcina mazei, were randomly distributed within non-halophilic methanogens (De Rosa et al., 1986a; 1986b; Becker et al., 2016). Therefore, we focused our analysis on Haloarchaea ( $\mathrm{N}=277$; Fig. 2A). Compound 2 was identified in the majority of currently known Natrialbales (51 out of 78 species, 16 out of 22 genera), but was more sporadically reported in Halobacteriales (32 out of 90 species, 14 out of 31 genera) and Haloferacales (6 out of 109 species, 2 out of 18 genera, i.e., Halorubrum and Halalkaliarchaeum). Such distinct distributions of $\mathbf{2}$ between the three Haloarchaea orders support the idea that factors controlling its biosynthesis are dependent on taxonomy (Dawson et al., 2012). Its wide distribution within Natrialbales would indicate that the ability to synthesize this compound is a common and ancestral feature of all the species of this order, while its patchy distribution within Haloferacales and Halobacteriales would suggest that members of these orders have sporadically gained this biosynthetic ability by horizontal gene transfers or spontaneous emergence. Another hypothesis to explain the distribution of $\mathbf{2}$ within Haloarchaea is that the ability to synthesize this lipid emerged and conferred increased fitness under peculiar environmental conditions, and was thus maintained.

In an effort to disentangle the contribution of taxonomy vs. stress response in the occurrence of $\mathbf{2}$ in Haloarchaea, we gathered from the literature the in-lab optimal growth conditions of all species with described membrane lipid compositions (Fig. 2B). To identify putative subgroups that might for instance result from the aforementioned influence of taxonomy, we represented our data using violin plots instead of typical box plots. Unlike the latter, violin plots represent the probability of a data point to be in a certain region of the plot (e.g., the larger the region the more data points it contains) and thus better depicts the data set distribution. Results showed that Haloarchaea synthesizing 2 grow optimally at significantly higher $\mathrm{pH}(7.45$ vs. $7.30, P$-value $=0.015)$ and salinity (200 vs. $190 \mathrm{psu}, P$-value $=0.035$ ) than non-producing species (Fig. 2B). However, although significant, these differences appeared rather small to support a major influence of growth $\mathrm{pH}$ and/or salinity on the biosynthesis of $\mathbf{2}$. This nonetheless hints that $\mathbf{2}$ may have played a role in the (long-term) adaptation of Haloarchaea to $\mathrm{pH}$ and salinity variations. Looking more closely at their optimal growth conditions, species capable of the synthesis of $\mathbf{2}$ are distributed within two distinct groups: one composed mostly of neutrophilic Haloarchaea (median $\mathrm{pH}=7.2$ ) and one of alkaliphilic Haloarchaea, mostly Natrialbales (median $\mathrm{pH}=9.2$; Fig. $2 \mathrm{~B}$ ). Such a bimodality suggests that two 

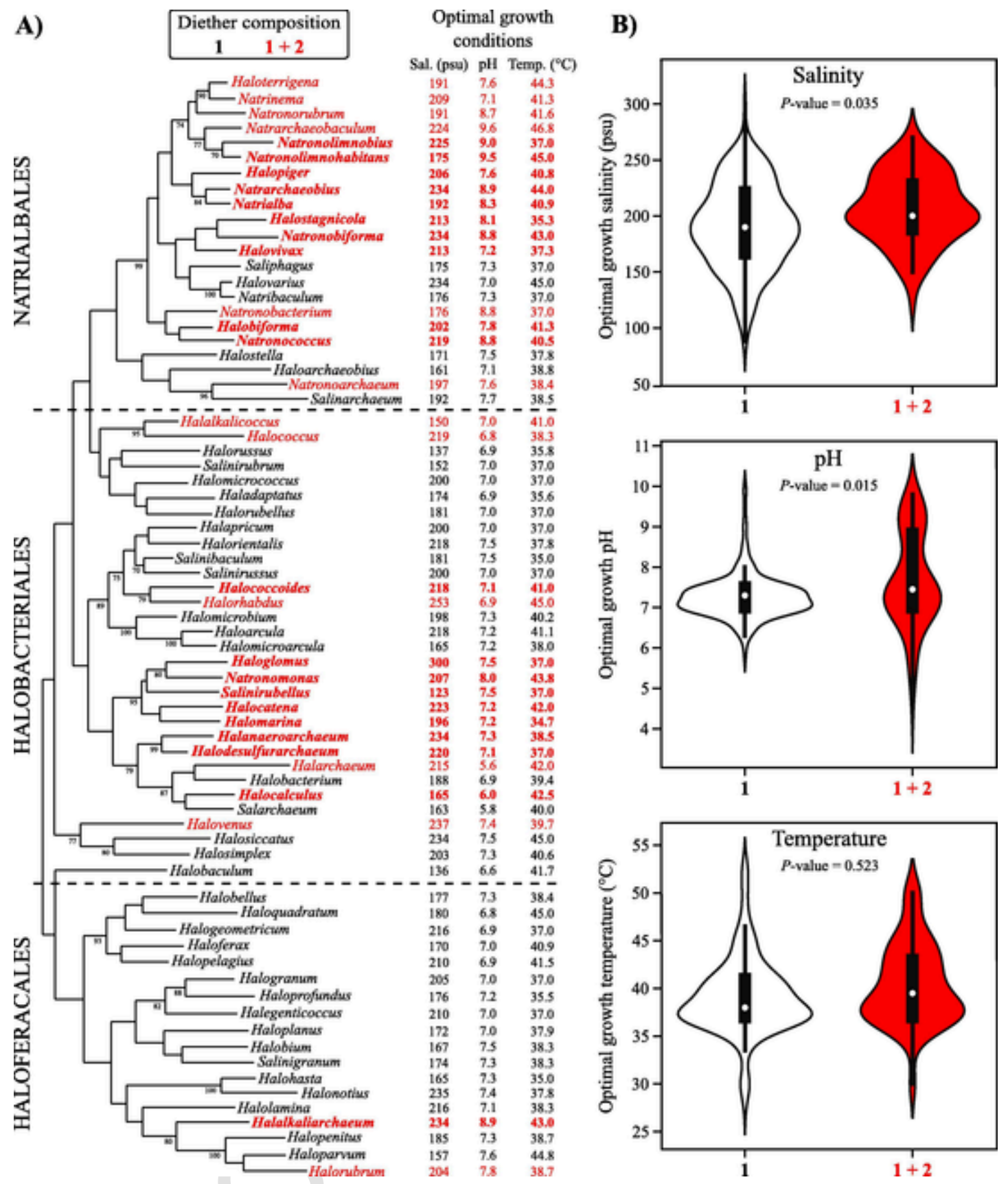

Fig. 2. A) Archaeal phylogenetic tree (redrawn from Cui and Dyall-Smith, 2021) and average optimal growth parameters (salinity, $\mathrm{pH}$ and temperature) of Haloarchaea. Genera highlighted in red illustrate the presence of $\mathbf{2}$ in at least one species; genera in bold red are those for which all species were reported to produce $\mathbf{2}$. B) Distribution of optimal growth parameters among Haloarchaea producing (red) or not (white) extended archaeol 2 (literature data). Violin plots include the medians (white dots), 1st and 3rd quartiles (black box limits), ranges (black whiskers) and probability densities (shape width). (For interpretation of the references to colour in this figure legend, the reader is referred to the web version of this article.)

confounding parameters, i.e., taxonomy and adaptation, might contribute to the distribution of $\mathbf{2}$ within Haloarchaea. For instance, $\mathbf{2}$ might support adaptation towards extreme $\mathrm{pH}$ in Natrialbales, while it might provide other yet unknown advantage in Haloferacales and Halobacteriales.

Our statistical analysis further showed that the occurrence of $\mathbf{2}$ is not correlated to the optimal growth temperature of Haloarchaea $(P$ value $=0.523$; Fig. $2 \mathrm{~B}$ ). This suggests that temperature have not exerted a significant control on the biosynthesis of $\mathbf{2}$ during the long-term evolution of this clade (Fig. S1A). It may not preclude, however, that temperature may influence the proportion of this lipid in the membrane of the archaeal producers during short-term acclimatisation (Yamauchi, 2008; Fig. S1A).

The current set of archaeal lipid compositions further places Haloarchaea as the main producers of $\mathbf{2}$. As the vast majority of currently known Haloarchaea are unable to thrive at salinity below 100 psu, the presence of 2 in sediments with salinity from ca. 40 to 100 psu is intriguing (Fig. 1B). However, 2 has been reported in non-halophilic species distinct from Haloarchaea (i.e., in non-halophilic methanogens; De Rosa et al., 1986b; Becker et al., 2016) and the lipid composition of numerous archaeal species is yet uncharacterized. The possibility that a whole range of producers of $\mathbf{2}$ besides Haloarchaea may contribute to the pool of this lipid biomarker in environments with contrasted salin- 
ity thus cannot be ruled out. On the other hand, Haloarchaea have been observed in a variety of sediment habitats that experience various levels of salinity (Youssef et al., 2012) including low or non-extreme saline environments such as estuaries (Purdy et al., 2004; Singh et al., 2010), sulfur-rich springs (Elshahed et al., 2004) or thiotrophic microbial mats (Jessen et al., 2016), suggesting that some (yet undescribed) low salttolerant Haloarchaea might be responsible for the production of $\mathbf{2}$ in settings with moderate salinity.

In spite of the still fragmented information currently available on the biosynthesis (producers and conditions) of extended archaeol, the present study encourages further investigation of the physiological role, environmental occurrence and potential use as (paleo)environmental indicator of this puzzling lipid.

\section{Uncited references}

Hou et al., 2018; Wang et al., 2015; Wang and Dou, 1998.

\section{Declaration of Competing Interest}

The authors declare that they have no known competing financial interests or personal relationships that could have appeared to influence the work reported in this paper.

\section{Acknowledgments}

We thank Mingda Wang for his valuable help in gathering the environmental parameters of the Tibetan lakes, Philippe Cuny for providing the sediments from salterns and Arnauld Vinçon-Laugier and Ingrid Antheaume for help with analyses. We thank two anonymous reviewers for their comments which greatly improved the manuscript. We are grateful to the CNRS Interdisciplinary program MITI 'Adaptation du vivant à l'environnement' (grant Adapthalo 2020-2021 to VG) and the ENS Lyon for their financial support.

\section{Appendix A. Supplementary material}

Supplementary data to this article can be found online at https:// doi.org/10.1016/j.orggeochem.2021.104276.

\section{References}

Becker, K.W., Elling, F.J., Yoshinaga, M.Y., Söllinger, A., Urich, T., Hinrichs, K.-U., Müller, V., 2016. Unusual butane- and pentanetriol-based tetraether lipids in

Methanomassiliicoccus luminyensis, a representative of the seventh order of Methanogens. Applied and Environmental Microbiology 82 (15), 4505-4516.

Birgel, D., Guido, A., Liu, X., Hinrichs, K.-U., Gier, S., Peckmann, J., 2014. Hypersaline conditions during deposition of the Calcare di Base revealed from archaeal di- and tetraether inventories. Organic Geochemistry 77, 11-21.

Cui, H.-L., Dyall-Smith, M.L., 2021. Cultivation of halophilic archaea (class Halobacteria) from thalassohaline and athalassohaline environments. Marine Life Science \& Technology 3 (2), 243-251.

Dawson, K.S., Freeman, K.H., Macalady, J.L., 2012. Molecular characterization of core lipids from halophilic archaea grown under different salinity conditions. Organic Geochemistry 48, 1-8.

De Rosa, M., Gambacorta, A., Gliozzi, A., 1986a. Structure, biosynthesis, and physicochemical properties of archaebacterial lipids. Microbiological Reviews 50, 70-80.

De Rosa, M., Gambacorta, A., Lanzotti, V., Trincone, A., Harris, J.E., Grant, W.D., 1986b. A range of ether core lipids from the methanogenic archaebacterium Methanosarcina barkeri. Biochimica et Biophysica Acta 875 (3), 487-492.

De Rosa, M., Gambacorta, A., Nicolaus, B., Ross, H.N.M., Grant, W.D., Bu'Lock, J.D., 1982. An asymmetric archaebacterial diether lipid from alkaliphilic halophiles. Microbiology 128 (2), 343-348.

Elshahed, M.S., Najar, F.Z., Roe, B.A., Oren, A., Dewers, T.A., Krumholz, L.R., 2004. Survey of archaeal diversity reveals an abundance of Halophilic archaea in a low-salt, sulfide- and sulfur-rich spring. Applied and Environmental Microbiology 70 (4), 2230-2239.

Hou, J., Tian, Q., Wang, M., 2018. Variable apparent hydrogen isotopic fractionation between sedimentary $n$-alkanes and precipitation on the Tibetan Plateau. Organic Geochemistry 122, 78-86.

Huguet, A., Grossi, V., Belmahdi, I., Fosse, C., Derenne, S., 2015. Archaeal and bacterial tetraether lipids in tropical ponds with contrasting salinity (Guadeloupe, French West Indies): Implications for tetraether-based environmental proxies. Organic Geochemistry 83-84, 158-169.

Jessen, G.L., Lichtschlag, A., Struck, U., Boetius, A., 2016. Distribution and composition of thiotrophic mats in the hypoxic zone of the Black Sea (150-170 m water depth, Crimea Margin). Frontiers in Microbiology 7, 1011.

Natalicchio, M., Birgel, D., Peckmann, J., Lozar, F., Carnevale, G., Liu, X., Hinrichs, K.-U. Dela Pierre, F., 2017. An archaeal biomarker record of paleoenvironmental change across the onset of the Messinian salinity crisis in the absence of evaporites (Piedmont Basin, Italy). Organic Geochemistry 113, 242-253.

Plancq, J., Cavazzin, B., Juggins, S., Haig, H.A., Leavitt, P.R., Toney, J.L., 2018. Assessing environmental controls on the distribution of long-chain alkenones in the Canadian Prairies. Organic Geochemistry 117, 43-55.

Purdy, K.J., Cresswell-Maynard, T.D., Nedwell, D.B., McGenity, T.J., Grant, W.D., Timmis, K.N., Embley, T.M., 2004. Isolation of haloarchaea that grow at low salinities. Environmental Microbiology 6 (6), 591-595.

Singh, S.K., Verma, P., Ramaiah, N., Chandrashekar, A.A., Shouche, Y.S., 2010. Phylogenetic diversity of archaeal 16S rRNA and ammonia monooxygenase genes from tropical estuarine sediments on the central west coast of India. Research in Microbiology 161 (3), 177-186.

Teixidor, P., Grimait, J.O., Pueyo, J.J., Rodriguez-Valera, F., 1993. Isopranylglycerol diethers in non-alkaline evaporitic environments. Geochimica et Cosmochimica Acta 57 (18), 4479-4489.

Tourte, M., Schaeffer, P., Grossi, V., Oger, P.M., 2020. Functionalized membrane domains: An ancestral feature of Archaea?. Frontiers in Microbiology 11, 526. Wang, S., Dou, H., 1998. A Directory of Lakes in China. Science Press, Beijing. Wang, M., Liang, J., Hou, J., Hu, L., 2015. Distribution of GDGTs in lake surface sediments on the Tibetan Plateau and its influencing factors. Science China Earth Science 59 (5), 961-974.

Wang, M., Tian, Q., Li, X., Liang, J., He, Y., Hou, J., 2020. TEX 86 as a potential proxy of lake water $\mathrm{pH}$ in the Tibetan Plateau. Palaeogeography, Palaeoclimatology, Palaeoecology 538, 109381. https://doi.org/10.1016/j.palaeo.2019.109381. Yamauchi, N., 2008. ESI-MS and GC-MS analyses of $\mathrm{C}_{25}-\mathrm{C}_{20}$ isoprenoidal diether originated from halophilic archaea with reference to an indicator for hypersaline environment. Researches in Organic Geochemistry 23-24, 123-130.

Youssef, N.H., Ashlock-Savage, K.N., Elshahed, M.S., 2012. Phylogenetic diversities and community structure of members of the extremely halophilic Archaea (Order Halobacteriales) in multiple saline sediment habitats. Applied and Environmental Microbiology 78 (5), 1332-1344. 